\title{
PETRA RACERUNNING: UMA EXPERIÊNCIA NA EDUCAÇÃO FÍSICA ESCOLAR
}

\section{PETRA RACERUNNING: AN EXPERIENCE IN SCHOOL PHYSICAL EDUCATION}

\author{
João Paulo Vicente da Silva ${ }^{31}$ \\ Fabyana Soares de Oliveira ${ }^{32}$ \\ Esmirna Silva Rezende Machado ${ }^{33}$ \\ Maria Aparecida Dias ${ }^{34}$
}

\begin{abstract}
Resumo
Este estudo apresenta uma experiência pedagógica desenvolvida em 2019 nas aulas de Educação Física de uma escola da rede municipal de Extremoz-RN, realizada na turma do 70 ano, com 30 alunos, sendo um diagnosticado com paralisia cerebral. Esta pesquisa busca analisar as vivências da Petra RaceRunning como conteúdo esporte adaptado nas aulas de Educação Física e no esporte de rendimento. Adota como delineamento metodológico uma abordagem qualitativa de caráter descritivo e exploratório. Como resultado, analisa e evidencia que a vivência sobre o conteúdo despertou mais motivação e autoestima no aluno com deficiência para a realização das atividades escolares, e ainda favoreceu o envolvimento, a participação ativa e a inclusão de todos os educandos nas aulas de Educação Física.
\end{abstract}

Palavras-chave: Educação Física. Esporte Adaptado. Paralisia Cerebral. Inclusão.

\section{Abstract}

This study presents a pedagogical experience developed in 2019 in Physical Education classes at a school in the municipal network of Extremoz-RN, held in the 7th grade class, with 30 students, one diagnosed with cerebral palsy. This research seeks to analyze the experiences of Petra RaceRunning as sports content adapted in Physical Education classes and performance sports. It adopts as a methodological design a qualitative approach of a descriptive and exploratory character. As a result, it analyzes and shows that the experience about the content aroused more motivation and self-esteem in

\footnotetext{
311 Mestrando em Educação Física pela Universidade Federal do Rio Grande do Norte UFRN, Departamento de Educação Física. Natal, Rio Grande do Norte, Brasil. Email: paulosilvarn@gmail.com ORCID: http://orcid.org/0000-0001-6678-2357

32 Doutoranda em Educação pela Universidade Federal do Rio Grande do Norte - UFRN, Centro de Educação, Natal, Rio Grande do Norte, Brasil. Email: fabyanaoliv@yahoo.com.br ORCID: https://orcid.org/0000-0001-6120-9105

33 Mestranda em Educação Física pela Universidade Federal do Rio Grande do Norte UFRN, Departamento de Educação Física. Natal, Rio Grande do Norte, Brasil. Email: esmirna rezende@hotmail.com ORCID: http://orcid.org/0000-0002-7069-0743

${ }^{34}$ Doutora em Educação pela Universidade Federal do Rio Grande do Norte - UFRN, Departamento de Educação Física, Natal, Rio Grande do Norte, Brasil. Email: cidaufrn@gmail.com ORCID: http://orcid.org/0000-0003-3644-604X
} 


\section{RevistAleph}

students with disabilities to carry out school activities, and also favored the involvement, active participation and inclusion of all students in Physical Education classes.

Keywords: Physical Education. Adapted Sport. Cerebral Palsy. Inclusion.

\section{A largada}

A Petra RaceRunning, como conteúdo esporte adaptado na escola, ainda é pouco conhecida e apresenta um número bem inferior de pesquisas sobre a temática, comparado a outros esportes adaptados. Além disso, entre os estudos existentes, a maioria volta-se para discussões a respeito da saúde, da atividade física, do rendimento, sem relacioná-los com o espaço escolar e suas possibilidades de vivência nas aulas de Educação Física. Esse fato é importante de ser destacado para iniciar nossa discussão.

De acordo com a União Metropolitana Paradesportiva de Maringá (UMPM) ${ }^{35}$, a modalidade RaceRunning (Petra) nasceu na Dinamarca, no ano de 1989. Foi criada por um paratleta, chamado Mansor Siddiqi, que acabou batizando a modalidade com esse nome como uma homenagem à mascote das Paralimpíadas de Barcelona, no ano de 1992, que se chamava Petra. Ao experimentar essa nova modalidade, ele demonstrou um incrível desempenho. No Brasil, a Petra teve início apenas em 2009, por meio da Associação Nacional de Desporto para Deficientes (ANDE), por intermédio do professor doutor Ivaldo Brandão e da fisioterapeuta Tania Frazão.

Posteriormente, a coordenação nacional da Petra RaceRunning foi assumida pelo professor doutor Décio Roberto Calegari (in memoriam), que teve um papel importante e fundamental para a expansão desse esporte adaptado. Hodiernamente, sua prática é vivenciada na maioria dos estados brasileiros. Sendo novidade no Brasil, poucas são as informações científicas sobre a Petra. Os dados apresentados neste estudo são oriundos da ANDE.

A Petra RaceRunning é um triciclo sem pedais, cuja mobilidade (caminhar ou correr) depende exclusivamente do esforço da pessoa, que se movimenta com seus

35 Entidade não governamental, sem fins lucrativos, com o propósito de desenvolver o paradesporto na região metropolitana de Maringá-PR. 


\section{RevistAleph}

próprios pés. Além da atividade esportiva, o triciclo é uma ferramenta que possibilita mais autonomia à pessoa com deficiência, principalmente em sua mobilidade em diferentes ambientes e contextos, tais como: atividade física recreativa, esporte, lazer, favorecendo o processo de inclusão da pessoa com deficiência. Em virtude dessas múltiplas possibilidades, compreendemos que a Petra RaceRunning poderá contribuir de forma significativa no ambiente escolar, sendo uma oportunidade de ampliar a interação de todos(as) os(as) alunos(as) de forma que passem a respeitar as diferenças e as pessoas que estão ao seu redor.

Quanto aos eventos esportivos, as competições da Petra RaceRunning são realizadas na pista de atletismo, com provas de 100 m, 200 m, 400 m, 800 m, 1.500 m e $5.000 \mathrm{~m}$. Além disso, os atletas são submetidos a uma classificação funcional ${ }^{36}$, que é utilizada para buscar o equilíbrio na competição e garantir a participação dos atletas. De acordo a Cerebral Palsy International Sports and Recreation Association (CPISRA), existem três classificações, são elas: RR1, RR2 e RR3.

Nossas motivações por essa temática se deram após a participação do curso Petra RaceRunning, promovido pelo Comitê Paralímpico Brasileiro (CPB), em São Paulo, que possibilitou a ampliação do conhecimento sobre esse esporte. Retornamos com uma inquietação ao conhecer essa nova possibilidade de trabalho. Com isso, iniciamos os estudos, objetivando novas oportunidades de vivências para os alunos nas aulas de Educação Física escolar, o que resultou na implementação da Petra RaceRunning no município de Extremoz-RN, por meio da Secretaria Municipal de Educação, em 2018.

Com a intenção de ampliar as discussões acerca do esporte, mediante o que vem sendo desenvolvido no município, objetivamos analisar as vivências da Petra RaceRunning como conteúdo esporte adaptado nas aulas de Educação Física escolar e no esporte de rendimento, visto que a hipótese deste estudo é que a Petra RaceRunning, inserida nas aulas de Educação Física escolar, possibilitará a inclusão da pessoa com deficiência física e sensibilizará as potencialidades dos demais estudantes

\footnotetext{
${ }^{36}$ É um processo contínuo pelo qual os atletas são submetidos à observação regular dos classificadores assegurando coerência e imparcialidade. 0 primeiro objetivo é determinar a elegibilidade para o atleta poder competir no esporte paralímpico e o segundo é agrupá-lo em determinada classe funcional esportiva (SOUZA, 2020, p. 17).
} 


\section{RevistAleph}

da turma, sendo possível, também, desenvolver uma proposta que possa unir as vivências pedagógicas e de rendimento. À vista disso, analisaremos, neste estudo, uma experiência pedagógica nas aulas de Educação Física escolar, realizada em uma escola pública do município de Extremoz-RN, em que consideramos a realidade e as possibilidades para o desenvolvimento desta proposta de trabalho.

\section{Diálogo sobre a Educação Física e a inclusão da pessoa com deficiência na escola}

A reflexão sobre a Educação Física escolar e a inclusão da pessoa com deficiência, em especial, a pessoa com paralisia cerebral, é uma tarefa complexa, carregada de profundas contradições e, muitas vezes, de práticas segregadoras, seletivas e excludentes, que não oportunizam a participação de todos os alunos no processo educacional. Percebemos, então, que a intervenção pedagógica nas aulas de Educação Física, bem como as discussões sobre a pessoa com deficiência, está enraizada no ambiente escolar, mas, ao mesmo tempo, rompe a fronteira dos muros escolares no processo de interação com toda a sociedade.

Nessa conjuntura, "Há um papel que, em toda circunstância, cabe aos educadores: o de facilitador do desenvolvimento humano para o enfrentamento de situações restritas, diminuidoras" (MORAIS, 2006, p. 9). Sob essa ótica, o papel do educador tem muito a contribuir para que os educandos possam compreender a pessoa com deficiência para além da deficiência e possibilitar um espaço inclusivo e de desenvolvimento de todos.

Segundo Melo e Martins (2004, p. 76),

[...] inserir os alunos com necessidades educacionais especiais na rede regular de ensino, particularmente aqueles com deficiência, é, portanto, o primeiro passo para garantir o acesso à aprendizagem e ao conhecimento.

Destarte, salientamos a importância de planejar e intervir para que as diferenças não originem a desigualdade e a exclusão na ação pedagógica, uma vez que 


\section{RevistAleph}

é necessário que todo e qualquer sujeito seja envolvido no processo educacional de forma efetiva.

Nessa concepção, as políticas educacionais devem garantir que todos os alunos aprendam juntos no ensino regular, respeitando a diversidade e as questões de sexo, raça, gênero, classe e as especificidades dos educandos. Assim, a escola deve estar aberta às diferenças, desenvolver discussões e reflexões junto à comunidade escolar para que a aprendizagem ocorra de maneira contínua e democrática.

Segundo Fonseca e Ramos:

Não há como negar que pessoas com deficiências são público alvo excluídos da sociedade ao longo da história e não é diferente nas aulas de Educação Física, principalmente considerando uma Educação Física que enfoque prioritariamente o rendimento físico e a performance (FONSECA; RAMOS, 2017, p. 189).

Diante disso, podemos perceber que muitos aspectos precisam ser ressignificados, havendo a necessidade da quebra de paradigmas com a efetiva inclusão das pessoas com deficiência na escola, nas aulas de Educação Física e na sociedade como um todo, tornando-se, assim, um espaço social, plural e de diferenças. Nesse aspecto, é importante considerar o conceito de inclusão de forma ampla, não pensando apenas no aluno com deficiência mas também buscando garantir o direito de todos e todas de vivenciarem a pluralidade de práticas corporais nas aulas de Educação Física escolar, uma vez que a inclusão educacional como política pública é um direito inalienável.

A partir desse processo de inserção do aluno com deficiência junto aos demais alunos, temos de considerar que "[...] não há cultura sem ambiente, nem corpo sem movimento, nem cultura sem corpo, nem movimento sem ambiente" (OKIMURA-KERR; ULASOWICZ; VENÂNCIO; SANCHES NETO, 2017, p. 26). Por conseguinte, é evidente a necessidade do diálogo constante na tentativa de entender que, no corpo, estão os sentimentos, as emoções, as expressões, a cultura e a história socialmente construída e transformada a todo momento. Considerando esses aspectos, Dias aponta que:

O corpo, necessariamente, torna-se produtivo, é olhado a partir da sua possibilidade de rendimento, é moldado para essa sociedade, é visto como corpo-objeto e não como um corpo sujeito, que possui emoção, história, memória, presente, passado e futuro. Quando entendemos 


\section{RevistAleph}

esse sujeito enquanto corpo e observamos a sua trajetória na História da Educação, nos damos conta do quanto o corpo continua sendo visto como objeto de produção por essa mesma educação (DIAS, 2012, p. 27).

Dessa maneira, faz-se necessário não descaracterizar a história construída e carregada em cada corpo, de cada educando, que dialoga e se transforma a partir das experiências. Dessa forma, cabe a nós, professores(as), perceber o sujeito com profundidade e não pelo olhar superficial que constitui uma identidade virtual e da relação de poder, sendo fundamental compreender a liberdade do olhar para esse corpo subjetivo, sensível e estético. Logo, acreditamos ser indispensável discutir sobre as possibilidades que garantam a inclusão da pessoa com deficiência, de forma que suas subjetividades e individualidades sejam consideradas durante o desenvolvimento das propostas de ensino. Partindo desse pressuposto, compreendemos que promover a inclusão contribui para uma educação de qualidade. Nesse processo de construção do saber, os(as) professores(as) de Educação Física escolar têm muito a contribuir, tendo em vista que ocupamos espaços políticos de inclusão e de transformação da realidade.

\section{O esporte adaptado e paralímpico nas aulas de Educação Física escolar}

O esporte é um dos conteúdos a ser explorado nas aulas de Educação Física escolar. Dentre as diversas possibilidades, podemos destacar, de forma mais específica, a discussão sobre o esporte adaptado. Desse modo, reconhecer que esse tipo de esporte trilha o enfrentamento da exclusão e repudia as diversas formas de preconceito e discriminação que tanto afligem a sociedade faz-nos entender a necessidade de intervir pedagogicamente para a diminuição do preconceito, buscando refletir sobre as mudanças de postura e as atitudes da comunidade escolar acerca da pessoa com deficiência, o que converge na necessidade de transformação da realidade sociocultural.

O resultado desta pesquisa aponta existir um entrelaçamento do esporte adaptado e paraolímpico. Essa correlação também está na escola e, sobretudo, quando tratamos da inclusão dos alunos com deficiência nas aulas de Educação Física. Segundo Silva et al., o esporte adaptado é: 


\section{RevistAleph}

[...] um termo utilizado apenas no Brasil e consiste em uma possibilidade de prática para pessoas com deficiência. Para tanto, regras, fundamentos e estrutura são adaptados para permitir a participação destas pessoas. Em outros idiomas, o termo mais comum é Esporte para pessoas com Deficiência ou "Sport for Persons with a Disability". Já o termo esporte Paralímpico designa as modalidades adaptadas que fazem parte do programa dos Jogos Paralímpicos [...] (SILVA et al., 2013, p. 680).

Além disso, o termo "atividade adaptada" tem suas nuances, pois podemos fazer adaptação em nossos movimentos ou em alguma atividade diariamente. Não se trata apenas de adaptação para as pessoas com deficiência. Por conseguinte,

Entende-se, assim, que o esporte para a pessoa com deficiência, seja ele adaptado de uma modalidade já existente, ou então criado exclusivamente para a prática de um determinado grupo, passa a integrar o tema esporte, entendido como um fenômeno que influencia a sociedade e por ela é influenciado. Dessa forma, o esporte praticado pelas pessoas com deficiência, pode integrar os temas trabalhados no esporte no âmbito escolar, passando, assim, a integrar o currículo da Educação física escolar (SALERNO; ARAÚJO, 2008, p. 216).

Dessa forma, o esporte inserido no ambiente escolar como conteúdo da Educação Física oportuniza as mais diversas formas de expressão. Por isso, é importante que o(a) professor(a) amplie as vivências nas mais diversas práticas corporais, buscando tornar as aulas mais atrativas e significativas para todos os alunos. Considerando a compreensão de uma Educação Física para todos, os alunos com deficiência devem estar incluídos ativamente no processo de ensino e aprendizagem que está sendo desenvolvido, assim como os demais alunos, sem excluí-los da proposta e sem desacreditar nas possibilidades de participação deles.

Ademais, perceber e ampliar as possibilidades nas aulas de Educação Física deveria ser uma preocupação de todos os(as) professores(as). Essas discussões e reflexões surgem para buscarmos mais entendimento sobre as diversas formas de atuação desses profissionais acerca do conteúdo esporte adaptado nas aulas de Educação Física escolar. 


\section{RevistAleph}

\section{Na pista metodológica}

Nesta pesquisa, adotamos uma abordagem qualitativa de caráter exploratório. De acordo Gil (2009, p. 27), a pesquisa exploratória tem “[...] como principal finalidade desenvolver, esclarecer e modificar conceitos e ideias, tendo em vista a formulação de problemas mais precisos ou hipóteses pesquisáveis para estudos posteriores". Nesse sentido, o autor acrescenta que:

\footnotetext{
Pesquisas exploratórias são desenvolvidas com o objetivo de proporcionar visão geral, de tipo aproximativo, acerca de determinado fato. Este tipo de pesquisa é realizado especialmente quando o tema escolhido é pouco explorado e torna-se difícil sobre ele formular hipóteses precisas e operacionalizáveis (GIL, 2009, p. 27).
}

Dessa forma, partimos da inquietação de trabalhar com o conteúdo esporte adaptado, levando em consideração que a Petra RaceRunning ainda é pouco explorada no ambiente escolar. Além disso, com o desenvolvimento desse esporte no espaço escolar, apontamos ser possível aproximar e despertar o interesse de todos os alunos, com ou sem deficiência.

A pesquisa ainda apresenta elementos da pesquisa descritiva, uma vez que os pesquisadores realizaram análises com base nas descrições acerca do fenômeno e de um grupo populacional. Para Gil (2009, p. 28), “[...] pesquisas descritivas são, juntamente com as exploratórias, as que habitualmente realizam os pesquisadores sociais preocupados com a atuação prática". Nesse aspecto, o processo de pesquisa, bem como da escolha dos procedimentos que adotamos, partiu de várias etapas que, gradativamente, foram se projetando e ganhando outras características com base na nossa ação pedagógica. Ao abordar a fundamentação metodológica, torna-se necessário discutir e traçar caminhos para que o pesquisador desenvolva sua pesquisa de forma que o objeto de investigação possibilite a transformação social, e, ainda, aprimorar as hipóteses e aumentar o entendimento acerca do conteúdo esporte adaptado nas aulas de Educação Física escolar com a vivência prática da Petra RaceRunning.

A pesquisa foi desenvolvida em 2019, nas aulas de Educação Física de uma escola da rede municipal de Extremoz-RN, em uma turma do 7ำ ano, com 30 alunos(as), 


\section{RevistAleph}

sendo um diagnosticado com paralisia cerebral. Utilizamos, para coleta de dados, registros no diário de campo, fotos e vídeos, possibilitando a identificação da realidade, bem como o diagnóstico de possíveis situações durante as aulas de Educação Física escolar observadas no início do ano letivo, de modo a compreender o campo de investigação. Nesse sentido, os dados analisados consistem na observação, nos discursos e na descrição das atividades desenvolvidas pelos(as) alunos(as).

\section{Em suas marcas: vai! Petra RaceRunning nas aulas Educação Física Escolar}

Partindo do delineamento traçado para a pesquisa, relataremos as experiências desenvolvidas nas aulas de Educação Física escolar. Para o desenvolvimento da proposta, estruturamos o processo em quatro momentos, sendo eles: 1ㅇ) observação e registro; 2의 planejamento da ação; 3ㅇ) desenvolvimento das aulas, considerando o conhecimento teórico e as vivências práticas da Petra RaceRunning como conteúdo esporte adaptado nas aulas de Educação Física escolar; 4ㅇ) interesse do aluno com deficiência em participar de atividades complementares de iniciação esportiva, bem como a participação em competições.

No que diz respeito ao primeiro momento, com observações e registros no diário de campo, fotos e vídeos, realizamos a identificação da realidade, buscando diagnosticar possíveis situações durante as aulas de Educação Física, a fim de compreender este campo de investigação. Percebemos que, durante a execução das atividades, seja em sala, seja na área externa da escola (pátio ou quadra), o aluno com deficiência não se sentia à vontade para interagir com os colegas de sua turma, mesmo o professor orientando passo a passo sobre o desenvolvimento da atividade.

Diante do diagnóstico inicial da realidade, detectamos a necessidade de modificar determinadas situações, uma vez que percebemos a falta de interação dos alunos da turma com o aluno com deficiência, em específico, o aluno com paralisia cerebral, sendo esse fato evidenciado na realidade das aulas de Educação Física. Com base nas observações feitas, iniciamos o diálogo com os alunos sobre algumas questões para nortear a discussão, buscando identificar o que a turma compreendia por preconceito, discriminação, se eles conseguiam perceber situações dessa natureza nas 


\section{RevistAleph}

aulas, como também fazer com que eles refletissem sobre os efeitos negativos causados às pessoas afetadas por atos e comportamentos de intolerância.

Em busca das possibilidades para resolver determinado problema detectado na realidade da turma, realizamos o segundo momento da pesquisa, referente ao planejamento da ação. Nessa perspectiva, escolhemos o conteúdo esporte adaptado para ser discutido e vivenciado nas aulas. Além disso, a escolha da modalidade Petra RaceRunning para aplicação nas aulas coincidiu com a necessidade de intervenção nessa realidade. A partir disso, surgiu o seguinte questionamento: como o conteúdo esporte adaptado pode contribuir para diminuir a falta de interação dos alunos com e sem deficiência na escola e ainda promover a sensibilidade acerca das potencialidades da pessoa com deficiência?

Acerca desse questionamento, apresentando a temática como possível conteúdo a ser discutido com a turma nas aulas de Educação Física, podemos considerar que o esporte:

[...] pelo seu sentido e significado plural, propicia a assunção significante do conhecimento teórico e prático a todos os corpos humanos, independentemente de suas disfunções e limitações. Esporte que, na leitura aqui apresentada, reveste do sentido da inclusão, minimizando sua história elitista. Corporeidade e desporto, aproximação possível e factível, colaborando no processo de humanização do ser humano (MOREIRA; PORTO; CARBINATTO; SIMÕES, 2008, p. 144).

Diante disso, percebemos que, com base no conteúdo esporte nas aulas de Educação Física escolar, de forma que tenha sentido e significado aos educandos, é possível dialogar com a realidade e propiciar o conhecimento numa perspectiva inclusiva, em que todos possam participar da proposta de ensino e aprendizagem, considerando as especificidades de cada um.

Partimos, então, para o terceiro momento da pesquisa, com o desenvolvimento das aulas, considerando o conhecimento teórico e as vivências práticas da Petra RaceRunning como conteúdo esporte adaptado nas aulas de Educação Física escolar. Antes de efetivar a aplicação de um conteúdo, é necessário que a ação do planejar esteja envolvida nesse processo. Segundo Libâneo, planejamento é: 


\section{RevistAleph}

[...] uma tarefa docente que inclui tanto a previsão das atividades didáticas em termos da sua organização e coordenação em face dos objetivos propostos, quanto a sua revisão e adequação no decorrer do processo de ensino. O planejamento é um meio pra se programar as ações docentes, mas é também um momento de pesquisa e reflexão intimamente ligado à avaliação (LIBÂNEO, 1994, p. 221).

Nesse sentido, compreendemos que o planejamento é um instrumento contínuo de orientação, e, ainda, suporte para eventuais mudanças no desenvolvimento da ação pedagógica, sendo ele dinâmico para que atenda as necessidades do processo de ensino e aprendizagem. Desse modo, foi possível perceber a importância dessa ação pedagógica não só para envolver o aluno com deficiência nas aulas de Educação Física, mas também para a formação dos demais alunos que fazem parte da turma. Assim, entendemos que, no processo de inclusão, é essencial garantir um espaço onde todos sejam reconhecidos como sujeitos ativos na vida social. No Quadro 1, a seguir, estão os dados relacionados a: planejamento das ações, número de aulas, metodologia e recursos didáticos utilizados durante as aulas com o conteúdo esporte adaptado Petra RaceRunning.

Quadro 1: Planejamento das ações

№ de aulas Objetivos
Planejamento das aulas

Apresentar e discutir os aspectos históricos e sociais dos esportes adaptados no Brasil; Reconhecer alguns tipos de deficiências e suas características.

\begin{tabular}{|c|c|c|c|}
\hline $\begin{array}{l}3 \text { aulas teóricas de } \\
60 \text { minutos, sobre } \\
\text { a pessoa com } \\
\text { deficiência e o } \\
\text { esporte adaptado }\end{array}$ & $\begin{array}{l}\text { Promover a cooperação e a } \\
\text { discussão dos alunos na } \\
\text { realização das atividades; } \\
\text { Possibilitar uma visão crítica e } \\
\text { reflexiva acerca das questões } \\
\text { inerentes à inclusão, ao } \\
\text { respeito às diferenças e ao } \\
\text { preconceito. }\end{array}$ & $\begin{array}{l}\text { Apresentar e discutir os } \\
\text { aspectos históricos e sociais } \\
\text { dos esportes adaptados no } \\
\text { Brasil; } \\
\text { Reconhecer alguns tipos de } \\
\text { deficiências e suas } \\
\text { características. }\end{array}$ & $\begin{array}{l}\text { Projetor } \\
\text { multimídia; } \\
\text { vídeos. }\end{array}$ \\
\hline $\begin{array}{l}4 \text { aulas de } 60 \\
\text { minutos de } \\
\text { vivência prática. }\end{array}$ & $\begin{array}{l}\text { Oportunizar os alunos a } \\
\text { vivência prática do esporte } \\
\text { adaptado Petra RaceRunning. }\end{array}$ & $\begin{array}{l}\text { Conhecer o triciclo de } \\
\text { corrida Petra RaceRunning; } \\
\text { Vivenciar a prática do } \\
\text { esporte adaptado nas aulas } \\
\text { de Educação Física. }\end{array}$ & $\begin{array}{l}\text { Triciclo de } \\
\text { corrida Petra } \\
\text { RaceRunning; }\end{array}$ \\
\hline
\end{tabular}

Fonte: autores, 2020.

O Quadro 1 tem o propósito de apresentar e discutir as questões sobre as dimensões conceitual, atitudinal e procedimental do conteúdo, tendo em vista a 


\section{RevistAleph}

importância de os alunos compreenderem conceitos acerca das práticas, das atitudes ligadas aos princípios de inclusão e respeito às diferenças, como também sobre as vivências práticas, com base nas quais os alunos foram estimulados a realizar as mudanças nas regras para o desenvolvimento do esporte adaptado nas aulas de Educação Física. Nessas aulas, estimulamos discussões sobre esporte, conectando esse tema com as situações destacadas durante a observação, relacionadas ao contexto da turma, que corresponde à não interação do aluno com paralisia cerebral. Com isso, buscamos desenvolver estratégias nas quais a cultura do diálogo estivesse sempre presente, como também provocamos a reflexão sobre as atitudes e formas de lidar com o próximo, possibilitando o envolvimento entre toda a turma.

À vista disso, dialogamos com Freire, quando aponta que:

Qualquer que seja a atividade proposta pelo professor ou escolhida pelas crianças, num espaço de autonomia, haverá sempre motivo para que as regras sejam construídas e praticadas, isto é, para o estabelecimento de normas que regulem as relações do grupo (FREIRE, 2009, p. 148).

Nessa perspectiva, o desenvolvimento das aulas partiu do princípio de que os alunos compreendessem a necessidade de propostas em que todos pudessem participar. Para isso, as regras eram flexíveis a mudanças de acordo com a necessidade do grupo, sejam regras propostas pelo professor, sejam construídas pelos educandos. Sob esse viés, compreendemos a importância de possibilitar autonomia ao aluno, oportunizando uma educação para a democracia, o respeito mútuo e a responsabilidade social. Assim, o respeito às diferenças é compreendido também como um processo dialógico e construtivo.

Na primeira aula, ao abordar como tema o esporte adaptado e a pessoa com deficiência, os alunos ficaram inquietos com o assunto. Por isso, buscamos outros elementos para aprofundar o conteúdo, sendo essa uma oportunidade para compreender nossas relações, percebendo a importância de um olhar sensível para com o outro.

Considerando essa proposta, optamos por desenvolver uma vivência, em que trabalhamos o atletismo, nesse caso, a inclusão do conteúdo esporte adaptado 


\section{RevistAleph}

denominado Petra RaceRunning. Destarte, surgiu uma nova oportunidade, a de "mergulhar" no movimento paralímpico, compreendendo suas peculiaridades e potencialidades. Na apresentação do triciclo, os alunos ficaram impressionados e curiosamente questionaram:

- Professor, como vamos "andar"? Não tem pedal.

- Qual a velocidade que pode chegar?

- Que bicicleta estranha, nunca vi.

- Quem pode andar? (Dados da pesquisa, 2019).

Essas inquietações e curiosidades são salutares devido à novidade. Então, na contextualização feita, discutimos sobre o esporte, destacando a história e algumas regras. Na sequência, os alunos foram convidados a vivenciar a prática dessa modalidade na área externa da escola. No decorrer da atividade, um fato interessante ocorreu quando os alunos de outras turmas observaram os alunos da turma pesquisada caminhando e correndo na Petra RaceRunning, o que levou a saírem de suas salas para observar. Uma das cenas que deve ter chamado a atenção foi a do aluno com paralisia cerebral (que usa cadeira de rodas) caminhando e correndo, participando de forma efetiva da atividade.

A esse respeito, corroboramos com Kunz, quando afirma que o:

[...] interesse pedagógico da Educação Física pelos esportes, o objeto de estudo deveria se concentrar mais sobre todas as formas de manifestação humana e de forma contextualizada, em que ser humano e movimento são relevantes tanto ao agir e pensar como para as relações entre os próprios homens [tenham eles deficiência ou não] (KUNZ, 2006, p. 67).

Nesse sentido, é importante que o(a) professor(a) seja capaz, em seu planejamento, de refletir sobre a sua prática pedagógica a partir do conteúdo esporte, para que ela sirva para todos os alunos. Assim, a proposta do trabalho pedagógico com o conteúdo esporte nas aulas de Educação Física escolar torna-se um elemento necessário no processo de aprendizagem da cultura de movimento e da manifestação social do sujeito.

Diante do que foi desenvolvido na primeira e segunda aula, percebemos que foi possível despertar, de forma inicial, o olhar sensível para as pessoas com deficiência. 


\section{RevistAleph}

Com base na repercussão e no diálogo realizado com os alunos, passamos a fazer algumas apresentações deste trabalho nas demais salas de aula. Nessa oportunidade, os olhares e a sensação de possibilitar a participação de todos foi um aspecto muito significativo para todos nós, pois evidenciamos a alegria e o envolvimento dos alunos durante o processo de intervenção. Além disso, identificamos que, no transcorrer das aulas sobre o esporte adaptado, houve o interesse do aluno com deficiência, bem como de sua família de ampliar aquela atividade para um atendimento especializado no contraturno das suas aulas.

Dando sequência, no quarto momento da pesquisa, que corresponde a investigar o interesse do aluno com deficiência em participar de atividades complementares de iniciação esportiva do projeto Extremoz Paralímpica, implementado em 2017 pela Secretaria Municipal de Educação de Extremoz-RN, bem como de competições. Na condição de professor da escola e do projeto da Secretaria, foi possível estabelecer esse diálogo entre ambos os espaços para efetivar a inclusão do educando.

Ademais, com a ampliação do atendimento especializado, devido ao interesse do aluno com deficiência, buscamos a autorização da Secretaria Municipal de Educação para oferecermos atividades complementares de iniciação esportiva. Com isso, outros alunos com deficiência também foram incluídos nesses atendimentos.

No que diz respeito ao atendimento especializado em atividades esportivas, é fundamental deixar explícito que esta proposta é pedagógica, não buscamos como objetivo formar atletas de alto rendimento, pois as vivências acontecem de forma recreativa, oportunizando momentos de lazer e aprendizagem. No entanto, com o passar do tempo, alguns alunos demonstraram interesse em participar de competições, o que nos surpreendeu, mas compreendemos também como uma possibilidade que não podemos negar aos alunos. Nesse aspecto, podemos considerar que:

A Educação Física enquanto área, por exemplo, passa a fazer parte deste processo de descoberta de possibilidades de intervenção, mais precisamente através do esporte, acenando para a possibilidade de reconstrução de caminhos alterados em decorrência de conflitos entre os povos há tempos atrás e hoje por diferentes motivos. Incorpora em suas ações, seja na formulação de propostas pedagógicas, na 


\section{RevistAleph}

descoberta de possibilidades, nas adaptações de metodologias, na reorganização de seus enfoques o propósito de promover a atividade física e o esporte para as populações em condições de deficiência (ARAÚJO; SILVA; CALEGARI, 2010, p. 473).

Nessa direção, iniciamos uma nova jornada. Observamos essa prática como uma nova possibilidade e um desafio para a Educação Física escolar, sobretudo no sentido de desenvolver atividades com o esporte adaptado e paralímpico na escola. Além disso, o intuito era promover a reflexão da prática, favorecendo a inclusão também fora dos muros escolares.

No atendimento especializado, procuramos desenvolver e avaliar outras capacidades (força, resistência e flexibilidade). Assim, a partir de um conjunto de atividades desenvolvidas, foi possível proporcionar mais qualidade de vida e inclusão aos participantes. Nesse aspecto, a ampliação das atividades psicomotoras é necessária para que o aluno possa desenvolver competências e habilidades que lhe possibilitem recursos substanciais para o enfrentamento das mazelas sociais, de forma que tenha condições para intervir e contribuir na sua resolução.

Dentre essa sistemática, podemos destacar como fator positivo a presença das famílias e as possibilidades do diálogo e de trocas efetivas sobre o desenvolvimento dos educandos. Como exemplo, trazemos o discurso de uma mãe com a seguinte informação: "Professor, minha filha está com mais disposição, alegre. Só fala nesse esporte". Esse discurso reforça a hipótese de que é possível promover a inclusão a partir das aulas de Educação Física escolar com base numa pedagogia que valorize as diferenças, o diálogo e que considere os alunos como atores do processo, contribuindo com a construção de uma prática escolar mais participativa e democrática, além de estimular a busca de outros meios fora do âmbito escolar que promovam o envolvimento, de forma efetiva, dos educandos com deficiência, como é o caso do atendimento especializado.

Durante essas descobertas vivenciadas nas aulas de Educação Física escolar e, posteriormente, no atendimento especializado com a prática esportiva, os alunos com paralisia cerebral se envolveram com o esporte Petra RaceRunning. Em 2019, inscrevemos um aluno no Circuito Regional Norte-Nordeste de Atletismo das Loterias 


\section{RevistAleph}

da Caixa em João Pessoa-PB. Nessa competição, logramos duas medalhas de ouro nas provas de 100 e 200 metros. Como resultado, foi perceptível a felicidade do aluno em conseguir superar seus limites, principalmente por sua interação com os outros competidores e as pessoas que estavam presentes no evento. Desse modo, podemos pontuar que esse é um encontro de transformação de vidas.

Nesse contexto, é importante destacar a iniciativa do Comitê Paralímpico Brasileiro (CPB) pelo fomento à formação de professores(as) de Educação Física escolar e pela realização de grandes eventos, incluindo crianças e jovens nas diversas modalidades esportivas. Como exemplo, podemos citar o Seminário Paralímpico Escolar e as Paralimpíadas Escolares. Diante dessas considerações, dialogamos com o Coletivo de Autores com base nas seguintes reflexões:

[...] os conteúdos da cultura corporal a serem apreendidos na escola devem emergir da realidade dinâmica e concreta do mundo do aluno. Tendo em vista uma nova compreensão desta realidade social, um novo entendimento que supere o senso comum, o professor orientará, através dos ciclos, uma nova leitura da realidade pelo aluno, com referência cada vez mais amplas (SOARES et al., 2012, p. 85).

Hodiernamente, compreendemos que tanto a vivência do esporte adaptado na escola quanto a do esporte de rendimento são possíveis de proporcionar aos alunos uma experiência que avaliamos ser inclusiva. O esporte de rendimento pode favorecer o desenvolvimento da criatividade, da consciência corporal, da interação social e da autoestima.

No entanto, ressaltamos a importância de tensionar as duas "linhas" de trabalho, ou seja, entendemos a necessidade de não supervalorizar uma em detrimento de outra, sobretudo quando tratamos de Educação Física escolar. É nesse sentido que destacamos o equilíbrio do esporte adaptado desenvolvido na escola e no rendimento, e, assim, percebemos que um depende do outro para a formação integral da pessoa com deficiência. Levando em conta as atitudes e os olhares, identificamos ainda a satisfação dos alunos em vivenciar a prática da Petra RaceRunning, o que nos faz refletir sobre a importância de possibilitar as diversas vivências corporais no ambiente escolar, espaço este que necessita de uma intervenção do(a) professor(a) de Educação Física, para que 


\section{RevistAleph}

este(a) não limite o acesso à cultura de movimento, nem negue o direito de formação integral do sujeito.

Considerando o momento de grande importância vivenciado pelos alunos por meio da participação na competição, enfatizamos a relevância da inclusão das pessoas com deficiência no esporte de rendimento e no esporte escolar, relacionado a situações vivenciadas na escola, como também defendemos a necessidade de quebrar paradigmas de narrativas, que apontam que o esporte de rendimento é excludente/seletivo, e, dessa forma, não é oportuno nas aulas de Educação Física escolar. Entendemos que negar a oportunidade de os alunos vivenciarem a prática do esporte de rendimento, seja na escola, seja em outros ambientes, é restringir a ampliação da cultura de movimento e sua formação.

Essa temática pode e deve ser divergente e convergente ao mesmo tempo, pois esse diálogo torna-se importante e estrutura as discussões sobre a Educação Física escolar e suas possibilidades, sobretudo no processo de inclusão das pessoas com deficiência. Assim, diante das experiências vividas pelos alunos e a partir do diálogo entre a Educação Física escolar e a Petra RaceRunning como conteúdo esporte adaptado, defendemos o papel essencial da escola na construção de conhecimento científico e da formação para a cidadania, cuja responsabilidade é também de promover intervenções pedagógicas que favoreçam o respeito à diversidade e o repúdio a qualquer tipo de discriminação e preconceito.

Considerando as experiências vivenciadas pelos(as) alunos(as), corroboramos o que aponta o Coletivo de Autores, “[...] a avaliação do processo de ensino/aprendizagem é muito mais que simplesmente aplicar testes, levantar medidas, selecionar e classificar alunos" (SOARES et al., 2012, p. 85). A esse respeito, salientamos que não temos a intenção de avaliar o desempenho predominantemente motor ou fisiológico para buscar talentos esportivos, pois essa não é a função da escola. Além disso, compreendemos que tal ação serve para selecionar e segregar o(a) aluno(a). Nessa direção, o Coletivo de Autores aponta que:

A ênfase na busca do talento esportivo e no aprimoramento da aptidão física vem condicionando, em parte, a aula e o processo avaliativo, transformando a Educação Física escolar numa atividade 


\section{RevistAleph}

desestimulante, segregadora e até aterrorizante, principalmente para os alunos considerados menos capazes ou não aptos, ou que não estejam decididos pelo rendimento esportivo (SOARES et al., 2012, p. 97).

Diante do exposto, compreendemos que avaliar, no processo de ensino e aprendizagem nas aulas de Educação Física escolar, consiste em uma mediação dos conhecimentos e seus significados, considerando a socialização, a autonomia e, sobretudo, a reflexão crítica da realidade, de forma que os alunos participem de maneira ativa e efetiva de todo o processo. Nessa perspectiva, compartilhar com os alunos os critérios pedagógicos utilizados durante as aulas e os desafiar na construção do conhecimento é um elemento importante, visto que, nesse processo formativo, o aluno assume o seu papel de protagonista.

\section{Na linha de chegada}

Com base na experiência desenvolvida com o esporte adaptado nas aulas de Educação Física escolar e as experiências no esporte de rendimento, percebemos a necessidade de aproximação, do diálogo e da interação da turma com o aluno com paralisia cerebral. Destarte, percebemos a necessidade de assumirmos uma postura não só crítica mas também sensível da nossa prática. Nesse sentido, compreendemos a importância de as aulas de Educação Física escolar oportunizarem situações de aprendizagem coerentes com a realidade do aluno, a partir de práticas pedagógicas menos excludentes e que possam garantir a inserção de todos os alunos como atores do processo.

Entendemos que a cultura de movimento é uma possibilidade concreta para entender mais o homem como um todo e suas diferentes e variadas formas de interagir com o mundo. Como educadores(as), devemos proporcionar a interação do conhecimento, suas relações com o indivíduo e o meio em que está inserido.

Assim, foi possível evidenciar que houve melhorias na interação entre os alunos durante e após as vivências do conteúdo esporte adaptado nas aulas de Educação Física, a partir da Petra RaceRunning. Percebemos também o aumento da motivação e da 


\section{RevistAleph}

autoestima dos alunos com deficiência para realizar as atividades escolares. Enfim, analisamos que a experiência foi relevante para o processo de inclusão e estímulo à sensibilidade das potencialidades dos alunos com deficiência.

Diante do estudo desenvolvido, esperamos que a discussão sobre a temática possa contribuir para a área da Educação Física escolar, como também para que haja intervenções com o propósito de alto rendimento, trazendo uma perspectiva mais pedagógica nos atendimentos especializados de práticas esportivas para pessoas com deficiência. Além disso, esta pesquisa visa contribuir com estudos de outros(as) professores(as) sobre a inserção do esporte adaptado nas aulas, possibilitando um diálogo sobre o esporte e as situações que perpassam na realidade dos educandos e da escola.

Ademais, este estudo colabora com o campo de produções científicas sobre o esporte Petra RaceRunning, uma vez que ainda são poucas as publicações sobre esse esporte. Assim, esta pesquisa visa favorecer discussões sobre a inserção da Petra no âmbito escolar, partindo de uma intervenção pedagógica ao alto rendimento. Esperamos ainda que este estudo possa estimular o desenvolvimento de outras pesquisas, gerando a ampliação do conhecimento.

\section{Referências}

ARAÚJO, Paulo Ferreira; SILVA, Rita de Fátima da Silva; CALEGARI, Décio Roberto. O desporto adaptado: organização e configurações. In: MENDES, Enicéia Gonçalves; ALMEIDA, Maria Amelia (org.). Das margens ao centro: perspectivas para as políticas e práticas educacionais no contexto da educação especial inclusiva. Araraquara: Junqueira \& Marin, 2010. p. 469-481.

ASSOCIAÇÃO NACIONAL DE DESPORTO PARA DEFICIENTES. Modalidade Race Running. [2017]. Disponível em: http://ande.org.br/modalidades-petra/. Acesso em: 14 fev. 2020.

COMITÊ PARALÍMPICO BRASILEIRO. Atletismo. [2020]. Disponível em: https://cpb.org.br/modalidades/46/atletismo. Acesso em: 12 fev. 2020.

DIAS, Maria Aparecida. 0 corpo na pedagogia de Freinet. São Paulo: Editora Livraria da Física, 2012.

FONSECA; Michele Pereira de Souza da; RAMOS, Maitê Mello Russo. Inclusão em movimento: discutindo a diversidade nas aulas de Educação Física escolar. In: PONTES JÚNIOR, José Airton 


\section{RevistAleph}

de Freitas (org.). Conhecimentos do professor de Educação Física escolar. Fortaleza: EdUECE, 2017. p. 184-208.

FREIRE, João Batista. Educação de corpo inteiro: teoria e prática da educação física. 5. ed. São Paulo: Scipione, 2009. (Coleção Pensamento e ação na sala de aula).

GIL, Antonio Carlos. Métodos e Técnicas de Pesquisa Social. São Paulo: Atlas, 2009.

KUNZ, Elenor. Transformação Didático-Pedagógica do Esporte. 7. ed. Ijuí: UNIJUI, 2006.

LIBÂNEO, José Carlos. Didática. São Paulo: Cortez, 1994. (Coleção magistério; Série formação docente).

MELO, Francisco Ricardo Lins Vieira de; MARTINS, Lúcia de Araújo Ramos. O que pensa a comunidade escolar sobre o aluno com paralisia cerebral. Revista Brasileira de Educação Especial, Marília, v. 10, n. 1, p. 75-92, 2004.

MORAIS, Regis de. Motricidade humana e déficits existenciais. In: RODRIGUES, David Antônio (org.). Atividade Motora Adaptada à alegria do corpo. Porto alegre: Arte Médica, 2006. p. 315.

MOREIRA, Wagner; PORTO, Eline Tereza Rozante; CARBINATTO, Michele; SIMÕES, Regina. Do corpo à corporeidade: a arte de viver o movimento no esporte. In: RODRIGUES, David Antonio (org.). Os valores e as atividades corporais. São Paulo: Summus, 2008. p. 127-146.

OKIMURA-KERR, Tiemi; ULASOWICZ, Carla; VENÂNCIO, Luciana; SANCHES NETO, Luiz (org.). Educação física no ensino fundamental I: perspectiva de sistematização dos blocos de conteúdos temáticos. Curitiba: CRV, 2017.

SALERNO, Marina Brasiliano; ARAÚJO, Paulo Ferreira de. Esporte adaptado como tema da Educação Física escolar. Conexões, [s. I.], n. 6, p. 212-221, 2008. Disponível em: https://doi.org/10.20396/conex.v6i0.8637826. Acesso em: 10 fev. 2020.

SILVA, Anselmo de Athayde Costa e et al. Esporte adaptado: abordagem sobre os fatores que influenciam a prática do esporte coletivo em cadeira de rodas. Rev Bras Educ Fís Esporte, São Paulo, v. 27, n. 4, out./dez. 2013. Disponível em:

http://www.scielo.br/pdf/rbefe/v27n4/aop_1013.pdf. Acesso em: 15 fev. 2020.

SOARES, Carmem Lúcia et al. Metodologia do Ensino de Educação Física. São Paulo: Cortez, 2012.

SOUZA, João Paulo Casteleti. Classificação em esporte paralímpico baseada em evidência. 2020. 113 f. Tese (Doutorado em Educação Física) - Faculdade de Educação Física, Universidade Estadual de Campinas, Campinas, 2020.

UNIÃO METROPOLITANA PARADESPORTIVA DE MARINGÁ. Race Running (Petra). [201?]. Disponível em: http://umpm.org.br/petra-race-running/. Acesso em: 20 jul. 2020.

Recebido em: $13 / 01 / 2021$

Aprovado em: 05/05/2021 